\title{
ESTRUCTURA, POESÍA, TOTALIDAD Y FRAGMENTO EN MACHU PICCHU Y LA MANO DESASIDA [¿1954?-1980] DE MARTÍN ADÁN. APROXIMACIONES HACIA UNA NUEVA EDICIÓN ${ }^{(*)}$

\author{
STRUCTURE, POETRY, TOTALITY AND FRAGMENT IN MACHU PICCHU AND LA MANO \\ DESASIDA [1954?-1980] BY MARTIN ADAM. APPROACHES TO A NEW EDITION
}

\author{
FRANCO CAVAGNARO FARFÁN ${ }^{[*]}$ \\ (iD https://orcid.org/0000-0003-4133-3912 \\ cavagnaroff@gmail.com \\ Universidad Nacional Mayor de San Marcos (Perú)
}

Fecha de recepción: 29 de abril de 2019

Fecha de aprobación: 9 de febrero de 2020

\section{RESUMEN}

A partir de uno de sus viajes al Cusco, el poeta Martín Adán establece una oposición entre lo feble y la fortaleza, y traza una línea divisoria entre Lima y el Cusco. Es en este periodo que se da un cambio temático y de forma verbal en su obra con la publicación del primer fragmento de La mano desasida en 1961, cuyo referente es el Santuario de Machu Picchu. así la problemática de la totalidad y el fragmento desde sus correlatos textual y arqueológico. Esto como una forma de entender la vastedad del archivo que comprende al poema, el propio referente del canto, Machu Picchu, y otras estructuras prehispánicas: su carácter de patrimonio arqueológico inmueble, y considerando, al mismo tiempo, cómo son entendidas desde la poesía.

\section{PALABRAS CLAVE}

Machu Picchu; Martín Adán; poesía; patrimonio inmueble

\section{ABSTRACT}

Based on the affirmations of the poet Martín Adán in a journalistic article published in 1954, in one of his trips to Cusco, we will trace an opposition of the material and the structure that make up a change of verbal form and subject matter of the publication of the first fragment of La mano desasida in 1961, whose reference is the Machu Picchu Sanctuary. This allows us to reflect on the complexity between the limits of the Hispanic and the pre-Hispanic, and the processes of reuse of construction materials and reoccupation of space. Between knowledge and destruction that is a universal process in the evolution of time. We will thus assume the problematic of the totality and the fragment from its textual and archaeological correlates. This as a way of understanding the vastness of the file corresponding to the poet's archive and the referent of the poem itself, Machu Picchu, its character as a complete or fragmentary real archaeological heritage.

\section{KEYWORDS}

Machu Picchu; Martín Adán; poetry; property heritage

\footnotetext{
${ }^{*}$ ) Este artículo forma parte de una investigación multidisciplinaria sobre el patrimonio y la relación entre arqueología, arquitectura y literatura. Esta se inició con la redacción del artículo Más allá de la estética: Jorge Eduardo Eielson frente al legado prehispánico, y se extiende al tema de estructura, totalidad y fragmento en poesía. Además, complementa los descubrimientos y análisis del artículo La representación arqueológica del pasado en La sexta lámpara de Pablo de Santis.

(**) Licenciado en Literatura Hispánica por la Pontificia Universidad Católica del Perú. Ha publicado la novela El viaje (film de treinta minutos). Fue finalista en la Bienal de Novela Premio Copé 2011 con Me he puesto el traje aquel. En 2016 publicó Huaquero (una historia sobre la Historia), la cual junto con la anterior forman su Díptico del pasado. Actualmente cursa la Maestría en Arte Peruano y Latinoamericano en la Universidad Nacional Mayor de San Marcos.
} 
devenir Vol. 7, Nº13, ENERO - JUNIO 2020, PP. 121-134 - EsTUDIOS I ISSN 2312-7562 | E-ISSN 2616-4949

UNIVERSIDAD NACIONAL DE INGENIERÍA, LIMA

doi: https://doi.org/10.21754/devenir.v7i13.928

\section{Introducción}

El indigenismo como expresión pictórica y el neoperuano como estilo arquitectónico, pusieron en relieve a personajes y formas del mundo andino y prehispánico en la primera mitad del siglo XX. Estas corrientes se desarrollaron gracias al impulso de José Sabogal y su círculo de artistas, a las obras arquitectónicas de la Patria Nueva de Augusto B. Leguía y al uso político de algunas imágenes y formas prehispánicas. Contra esta tendencia, en 1939, el poeta César Moro escribió una crítica demoledora del indigenismo en la revista El uso de la palabra'.

A partir de los años cuarenta, poetas e intelectuales limeños recrearán ese legado aprehendiéndolo, directamente influenciados por los espectaculares hallazgos artísticos del Perú antiguo y las muestras museísticas, publicaciones y estudios que desde la ciencia arqueológica empezaban a concretarse y definirse en dicha década. Además, desde la visión del mundo andino y su impulso hacia la modernidad, la historiografía peruana adoptó una nueva forma de acercarse al pasado. Martín Adán, de quien se suele pensar como un representante de la tradición hispánica, es un capítulo inicial de ese acercamiento y este artículo trata de reconstruir y unir el contexto de su época y sus vínculos con otras ciencias a partir de la reflexión en torno a los materiales de construcción en la poesía (La mano desasida) y su primera narración (La casa de cartón).

\section{Quincha, adobe y piedra}

En una entrevista aparecida en Cultura Peruana en abril de 1954, Martín Adán declaró: "Yo no sé por qué he nacido en el Perú... No lo entiendo».Y, más adelante, agregó algo revelador: «Lima no tiene alma, en algunas cosas, las casas y el Palacio de Rospigliosi son pura 'quincha'. Aquí es diferente, hay fortaleza». (Milla, 1954, s.n.). Esto lo dijo haciendo referencia a su estancia en Cusco y se refiere a la conservación milenaria de la arquitectura cusqueña, si se le compara con la feble estructura de las casas limeñas, según se puede desprender de sus propias consideraciones. La quincha es un material usado desde tiempos prehispánicos. ¿Sería consciente del todo Martín Adán de ese origen? Y si fuera así, el hecho de que un castillo medieval, hecho de quincha, emplazado en Santa Beatriz, representara el aposento de un rey europeo en Lima, ino es algo impostado? En Machu Picchu. Sortilegio en piedra/ Enchatment in stone se afirma que:

(...) en la costa se edificaba desde remotos tiempos con adobes y adobones, y con quincha (cañas y barro, técnica que describe en detalle $\operatorname{Cobo}^{2}$ ), para el caso de las viviendas populares o los recintos pequeños en la parte superior de los templos. En la sierra, el material de construcción por excelencia era la piedra ${ }^{3}$. (Kauffmann, 2013, p. 397)

Según la experiencia como restaurador del arquitecto Diego Celis Estrada, el Castillo Rospigliosi fue construido en 1929. En dicho periodo las construcciones alcanzaban tres niveles, ya se usaba el ladrillo (en el primer nivel) y paneles con malla expandida (en los niveles superiores). Al hacer una visita al edificio, pudo reconocer que el edificio principal (cinco niveles) y las portadas laterales (tres portadas) fueron construidos bajo esta técnica constructiva. Mientras que en los casos de los torreones (dos niveles) que se encuentran en cada esquina, su primer nivel es de abobe y muros perimetrales (un nivel) son totalmente de adobe. Como consecuencia del terremoto de 1746, se inicia

\footnotetext{
1. Este artículo, A propósito de la pintura en el Perú, se puede leer en Prestigio de amor de César Moro, p. 315 321. Ver Referencias.

2. Bernabé Cobo (1582-1657), cronista y sacerdote jesuita, cuyos escritos más conocidos son la Historia de la Fundación de Lima y la Historia del Nuevo Mundo.

3. Kauffman aclara inmediatamente: «...sin embargo, se observan bases de piedra en muros costeños como en Chan Chan- así como construcciones de adobe y adobón en la sierra» (Op. cit., p. 397). Las negritas cuando no se indique que sea del propio autor de la obra citada son mías.
} 


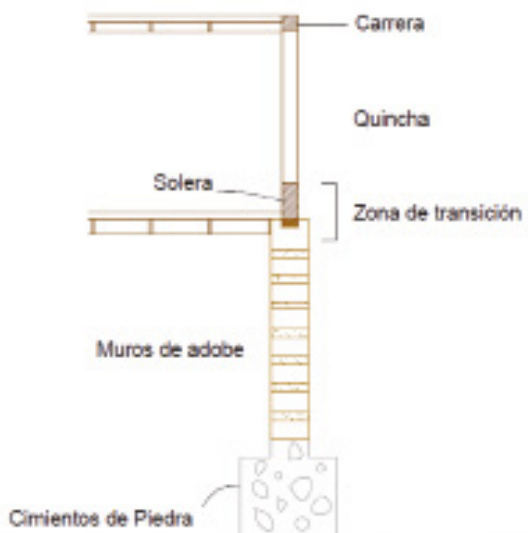

Figura 1. Técnica constructiva del abode, desarrollo en nota 11. Recuperado de http://bibing.us.es/proyectos/abreproy/5242/fichero/CAP\%C3\%8DTULO+1.pdf, 2019.

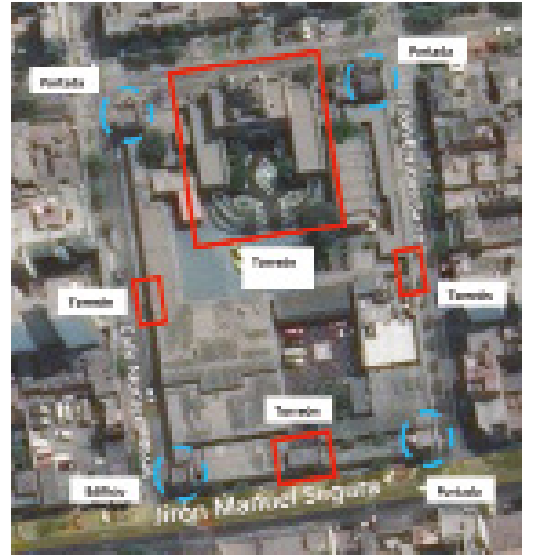

Figura 2. Planta del Castillo Rospigliosi. Elaborado por Diego Javier Celis Estrada, 2019.

el tránsito a esta técnica constructiva. Es decir, un primer nivel de material macizo y los niveles superiores de material ligero, para así contar con un centro de masa ubicado lo más inferior posible y de esta manera la edificación era más estable ante un movimiento telúrico.

Durante el virreinato (estilo barroco) las edificaciones contaban con dos niveles, el primer nivel era de bloques de adobe y el segundo nivel presentaba paneles de quincha. Cabe destacar que los paneles de quincha contaban con una peculiaridad que no se encuentra en la construcción de quincha actual. Esta peculiaridad era que los paneles presentaban una base de ladrillos o piedra (ver Figura 1), de esta manera le daba mayor estabilidad ya que su centro de masa se encontraba en la base.

A principio de la República (estilo neoclásico) se proyectan edificaciones de tres niveles. En el primer nivel se introduce el uso del ladrillo (albañilería simple), el segundo y tercer nivel seguían presentando paneles de quincha. En la primera mitad del siglo XX (estilo académico francés), el primer nivel continuaba siendo de ladrillo y si bien en el segundo y tercer nivel se seguía utilizando paneles de quincha, se comienzan a dejar de lado por paneles con malla expandidas y acabado en cuarzo ${ }^{4}$ (D. Celis, comunicación personal, 31 de enero de 2019) (ver Figura 2).

Volviendo a la inicial confrontación entre lo feble y la fortaleza, esta refleja también un parteaguas en la obra de Martín Adán y, al mismo tiempo, es un señalamiento del material en uso en la costa y la sierra, que no es una dualidad tan simple de establecer entre lo feble y la fortaleza. Unos años después, en 1961, se publica Nuevas piedras para Machu Picchu, una edición conmemorativa, a pedido de su editor Juan Mejía Baca, por el hallazgo, cincuenta años después, de Machu Picchu por Hiram Bingham. A partir de ese año, se conocerán diversas versiones del poema monumental en el que el poeta, se coloca en el centro del mundo andino (Cusco) y su universo.

La elección del tema del canto a Machu Picchu es por la solicitud de Juan Mejía Baca, aunque también ya desde la entrevista citada de 1954, hay referencia a la

\footnotetext{
4. Por otro lado, Christian Zegarra tiene un interesante artículo sobre el uso de otro material feble en Lima: "Un país de beaver board: cinematografía y nación desechable en La casa de cartón de Martín Adán". Sobre este aspecto en particular, la tesis que estamos desarrollando en la maestría incluye una larga reflexión de los materiales a partir de Adobe, tesis de Bachiller de la Facultad de Arquitectura Urbanismo y Artes de la UNI de Sofía Rodríguez Larraín. Por razones de espacio no lo abordaremos aquí. Ver Referencias.
} 
devenir Vol. 7, Nº13, ENERO - JUNIO 2020, PP. 121-134 - EsTUDIOS I ISSN 2312-7562 | E-ISSN 2616-4949

UNIVERSIDAD NACIONAL DE INGENIERÍA, LIMA

doi: https://doi.org/10.21754/devenir.v7i13.928

escritura de ese gran canto: «[l]a última producción de Martín versa sobre los viajes hechos a Machu Picchu, viajes frustrados, pues las dos veces, estando en el Hotel, no quiso conocer las ruinas, por temor a la altura». (Piñeiro, p. 30) No obstante, la presencia de lo prehispánico (o la alteridad ${ }^{5}$ ) en su obra anterior, casi no ha estado presente y, más bien, es un lejano relumbrón de un sol destructor y un sarpullido en los apuntes caleidoscópicos de su primera publicación prosística. La aproximación vanguardista en sus primeros poemas y en su conjunto prosaico, sobre todo La casa de cartón (1928), plantea una diástole y sístole de su propia verbalidad vanguardista, que luego irá de regreso al margen hispánico barroco. Al respecto se podría pensar en ese inicial:

Vanguardismo [como] el momento de la alianza táctica de todos los sectores antihispánicos (léase antioligárquicos) en el ordenamiento cultural peruano... Los hijos de la vanguardia conservaron su marginalidad y su vigencia todo lo que demoró la burguesía peruana en arrancarle la hegemonía política a los sectores oligárquicos que Mariátegui llamó descendientes espirituales de los «encomenderos» españoles. (Lauer, 1983, pp. 21-22)

Si proponemos una primera oposición espacial entre Lima y Cusco (y también temporal), como sus palabras parecen expresar en la entrevista de 1954, entonces La casa de cartón nos ofrece dos imágenes que nos interrogan más sobre las distancias (cognoscitivas, espaciales y simbólicas) dentro de los muros coloniales premodernos que irán depredando la presencia de las huacas milenarias, que de la forma como se irá transformando el paisaje fuera de esos muros. "Ahora el sol mastica jalde una cumbre serrana y una huaca, una mambla amarilla como el mismo sol» (Adán, 1974, p.14). Luego agrega: «Todo lo que está más allá de la sierra o del mar se acerca de pronto, meridiano a meridiano, en un hombre, por sobre las aguas morenas de la calzada (...) El campo, sarpullido de huacas, en la boca abierta de los jirones» (Ibídem, p. 20) ${ }^{6}$. Adicionalmente, sobre los museos y sus huacos se lee en La casa de cartón: "Ante [el jacarandá] dudamos como ante los huacos del Museo, que no sabemos si son de Nazca o de Chimú, si auténticos o falsificados, si negros o blancos». (Ibid., pp. 22-23)

Es en los años 20 cuando se investiga y divulga con mayor fuerza los vestigios prehispánicos. Apenas unos años después del descubrimiento de Machu Picchu en 1911, Julio C. Tello inicia su expedición y sus investigaciones en Chavín (1919), y unos años antes de la publicación de La casa de cartón, el mismo Tello llega a Paracas (1925). La

\footnotetext{
5. Así lo define Antonio Melis en La piedra obsesiva de Martín Adán, incluido en La suma que es el todo y que no cesa: el poema largo en la modernidad de M. Graña, pp. 135-147. Ver Referencias.

6. Segunda referencia a la boca: la del sol que mastica y la de los nuevos jirones urbanísticos, a punto de tragarse ese campo, sarpullido ¿nocivo? ¿Es esta la misma boca (que ya no come huacas sino hombres unas décadas después) cerrará Los gallinazos sin plumas de Julio Ramón Ribeyro: «la ciudad, despierta y viva, abría ante ellos su gigantesca mandíbula» (Ribeyro, 2000, p.39)? El escritor limeño además tiene una visión entre cómica y burlona de dos huaqueros de la Huaca Juliana en su cuento «Los huaqueros», no incluido en $L a$ palabra del mudo, publicado en El Dominical, suplemento cultural de El Comercio, 10 de junio de 2007, pp. 8-10.

7. Al referirse al Museo, el narrador podría estar señalando el Museo de Historia Nacional fundado en 1905 durante el periodo del Presidente José Pardo y Barreda (1904-1908), el cual estaba bajo la dependencia del Instituto Histórico del Perú, su inauguración se dio el 28 de julio de 1906. Fue Max Uhle quien se encargó de acrecentar las colecciones debido a su experiencia, excavando y comprando. Entregó dicho patrimonio arqueológico a una comisión el 23 de diciembre de 1911. Aunque es probable que se refiera al recientemente (entonces 1924) Museo Arqueológico construido por Larco Herrera (hoy Museo de la Cultura), pues allí casi lo único que había era huacos Nasca y Chimú que provenían de colecciones particulares, por lo que era dudoso su origen. Esta última es la opción más probable, ya que en el Museo de Historia Nacional casi no habían piezas de esta última cultura.
} 
arqueología ${ }^{8}$ adquiere además un prestigio académico que no había tenido, al tiempo que la propia urbanización (la modernización) de Lima corre a la par de su desarrollo. Un proceso de conocimiento y destrucción del que Martín Adán está rodeado.

Regresando al tema del material y su fortaleza, ese origen prehispánico de la quincha es también una paradoja en la construcción de un castillo europeo y recuerda la materia prima de las propias murallas de Lima, las cuales se derrumban para dar paso a la modernidad mientras el proceso de conocimiento y destrucción de las huacas prehispánicas durante toda la primera mitad del siglo XX, asimismo, es una paradoja y una doble destrucción: «en la época colonial se reutilizan los ladrillos de adobe de las huacas precolombinas para construir las murallas, las cuales se destruyen a partir de 1868». (Crousse, 2011, p. 213)

Dos décadas después George Kubler testimonia la continuidad de tal destrucción en su artículo Sobre arquitectura actual en Lima: «Al pie de casi toda gran huaca, una fábrica de ladrillos explota el trabajo de pasados tiempos (...) La arcilla que formaron manos indias en épocas pretéritas, pasa ahora por los hornos y va a dar a las casas de los suburbios» (Las Moradas, №6, 1948, p. 265). Doble uso de un material milenario en una nueva estructura. Permutación y cambio. ¿Será esta la falta de alma que encuentra el Adán maduro en la Lima de, 1954, producto de una insoslayable destrucción? El joven Ramón podría hacer eco del poeta ya maduro en Machu Picchu, como si se tratara de un acto de fe creer en la eterna permanencia de ese remanente:

¡Tú, que lo sabes todo, ruina reciente,

Revélame el misterio!

Soy una creatura

De las que hizo Dios en el Desierto.

Fúgate, yo contigo

¡No me dejes con el pensamiento!

Déjame ser una piedra,

Entre tus piedras y tus misterios,

Déjame ser uno vivo

Verdaderamente sin techo.

¡Que ninguna imagen me toque

Porque soy un hecho!

Es ist nun da wo Ich glaube ${ }^{10}$

Así escribía yo en el colegio.

Todo contigo se vino a mi vida,

Está por fin ahí, yo ya creo

(Adán, 1980, p. 259)

8. Sobre el proceso que aquí hemos mencionado sobre conocimiento, destrucción y prestigio arqueológiCo, ver El Neoperuano, arqueología, estilo nacional y paisaje urbano 1910-1940 de Gabriel Ramón Joffré. Sobre todo los capítulos «Expansión urbana y apropiación simbólica» y «La estela del Neoperuano» en relación a la desaparición de las huacas. Este mismo proceso es denunciado por Karl E. Meyer cuando habla acerca del desarrollo urbanístico en lugares como «Alburqueque, Santa Fe, Framington y Las Cruces in the early 1960s resultes in the flooding of five hundred archeological sites (...) We are witnessing the equivalent of the burning of the library at Alexandria by the Romans, the catastrophic bonfire in which much of the wisdom of antiquity was consumed in flames. One can see most of the ingredients of the conflagration in the rentless demolition of pre-Columbian sites». (Meyer, 1973, p. 12)

9. Personaje principal de La casa de cartón.

10. Traducción del autor: Ahora es donde creo. 
devenir Vol. 7, Nº13, ENERO - JUNIO 2020, PP. 121-134 - EsTUDIOS I ISSN 2312-7562 | E-ISSN 2616-4949

UNIVERSIDAD NACIONAL DE INGENIERÍA, LIMA

doi: https://doi.org/10.21754/devenir.v7i13.928

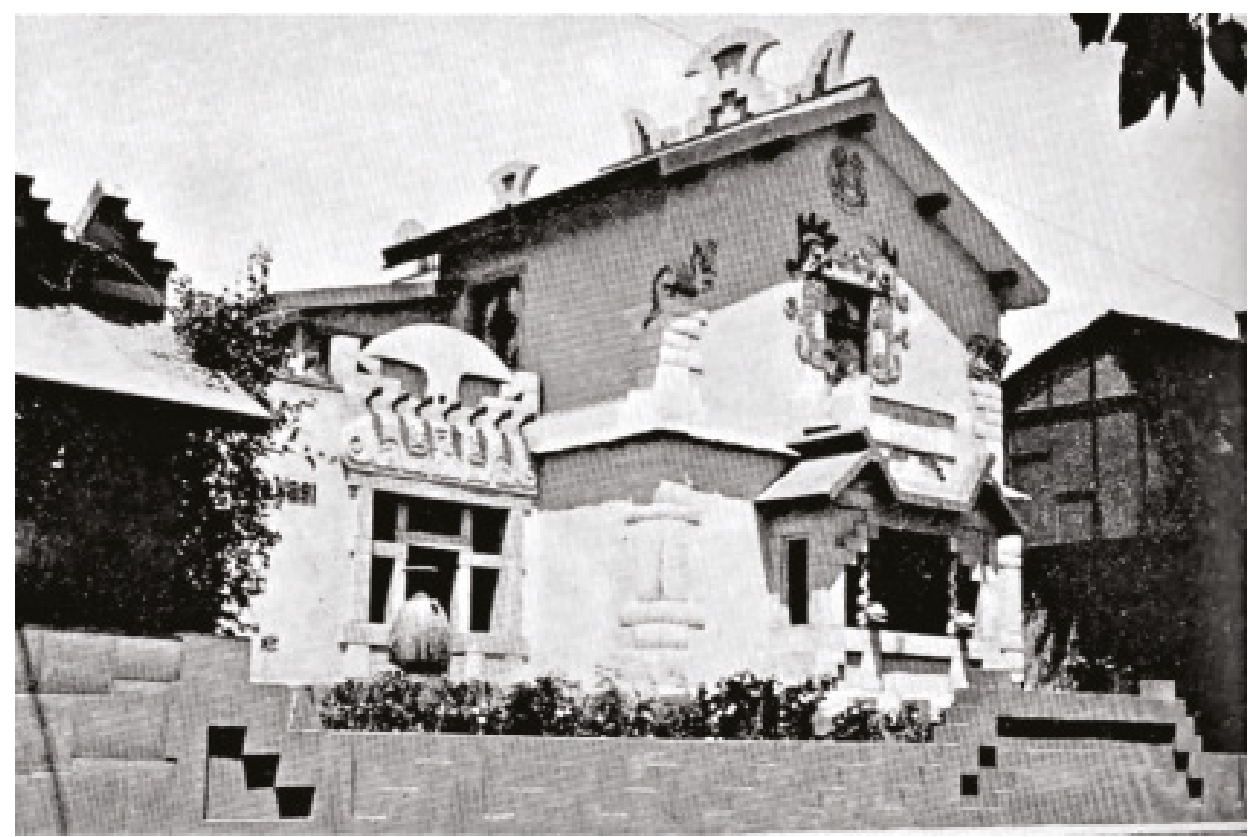

Figura 3. Casa de Julio C. Tello, Incawasi, Miraflores. Publicado por Gabriel Ramón, 2014.

¿Podríamos seguir a Kubler cuando en relación al progreso en la historia de la arquitectura, afirma: «por permutación y combinación, un depósito arquetípico de materiales y procesos vuelve una y otra vez a renovada vida»? (Las Moradas, №6, 1948, p. 265) Y, finalmente, ¿cuál o cuáles son esas huacas que el joven Ramón describe? ¿Cuáles de ellas sobreviven al conocimiento académico y su destrucción en aras del urbanismo ${ }^{11}$ ? Hay que tomar en consideración que en 1937, Martín Adán frecuentó el curso Civilización Tradicional Peruana (Época Prehispánica) en la Universidad Católica, el cual dictaba José de la Riva Agüero ${ }^{12}$. Al respecto se dice que

(...) a fines de la década de 1930, el mismo historiador empleará los materiales excavados por Alfred Kroeber en la huaca Aramburú y los conchales de Bellavista, Callao, estudiados por Max Uhle, para discutir la historia y la política peruana. Más puntualmente, Riva Agüero usará estas evidencias para rebatir los argumentos de algunos indigenistas. (Ramón, 2014, p. 52)

\footnotetext{
11. A la larga tradición de destrucción y/o de desprotección habría que agregar el DS 007-2017-MC que modifica el Reglamento de la Ley 28296, que tiene como finalidad dejar sin protección legal a los bienes culturales inmuebles. Roger Ravines hace un inventario en 1985 llamado Inventario de monumentos arqueológicos del Perú: Lima Metropolitana [primera aproximación].

12. La referencia acerca de la cercanía entre el baluarte del hispanismo en el Perú y el poeta, se puede encontrar en la biografía de Vargas Durand: "Luis Alberto Sánchez en sus memorias narra que hacia setiembre de 1930 presentó a Martín Adán, junto a otros jóvenes intelectuales, a José de la Riva Agüero al regresar éste del exilio". (Vargas, 1992, p. 56) Unas páginas después se asegura que sobre dicha relación "no hay noticias" (Ibídem p. 58) hasta el referido curso de 1937, cercanía la cual se manifestaría en "la dedicatoria de una de las copias mecanográficas de De lo barroco" (Ibíd., p. 65). En ella se lee: "Al doctor José de la Riva Agüero Osma, el ilustre historiador y maestro del Perú, este ejemplar y la tesis misma, indigna de su atención, pero, en mí, dentro de mí, inspirada en su obra y designio admirables". (Ibíd., p. 94) En la misma página del libro de Vargas Durand se afirma que "Adán había también participado de la tertulia del maestro en la casa de éste en Chorrillos", refiriéndose a Riva Agüero. Además se puede leer sobre el uso de los hallazgos en la huaca Aramburú y los Conchales para los mencionados debates nacionales acerca la matriz (o la raíz) serrana o costeña de la cultura andina en el capítulo 5 Fijar la raíz del libro citado: El Neoperuano, arqueología, estilo nacional y paisaje urbano 1910-1940. Sirva todo lo anterior para recordarnos las tertulias en la casa de Eguren, cuyo grupo se autodenominaba Los duendes, cuando Martín Adán cursaba el 4to de media (Ibíd, p. 29).
} 


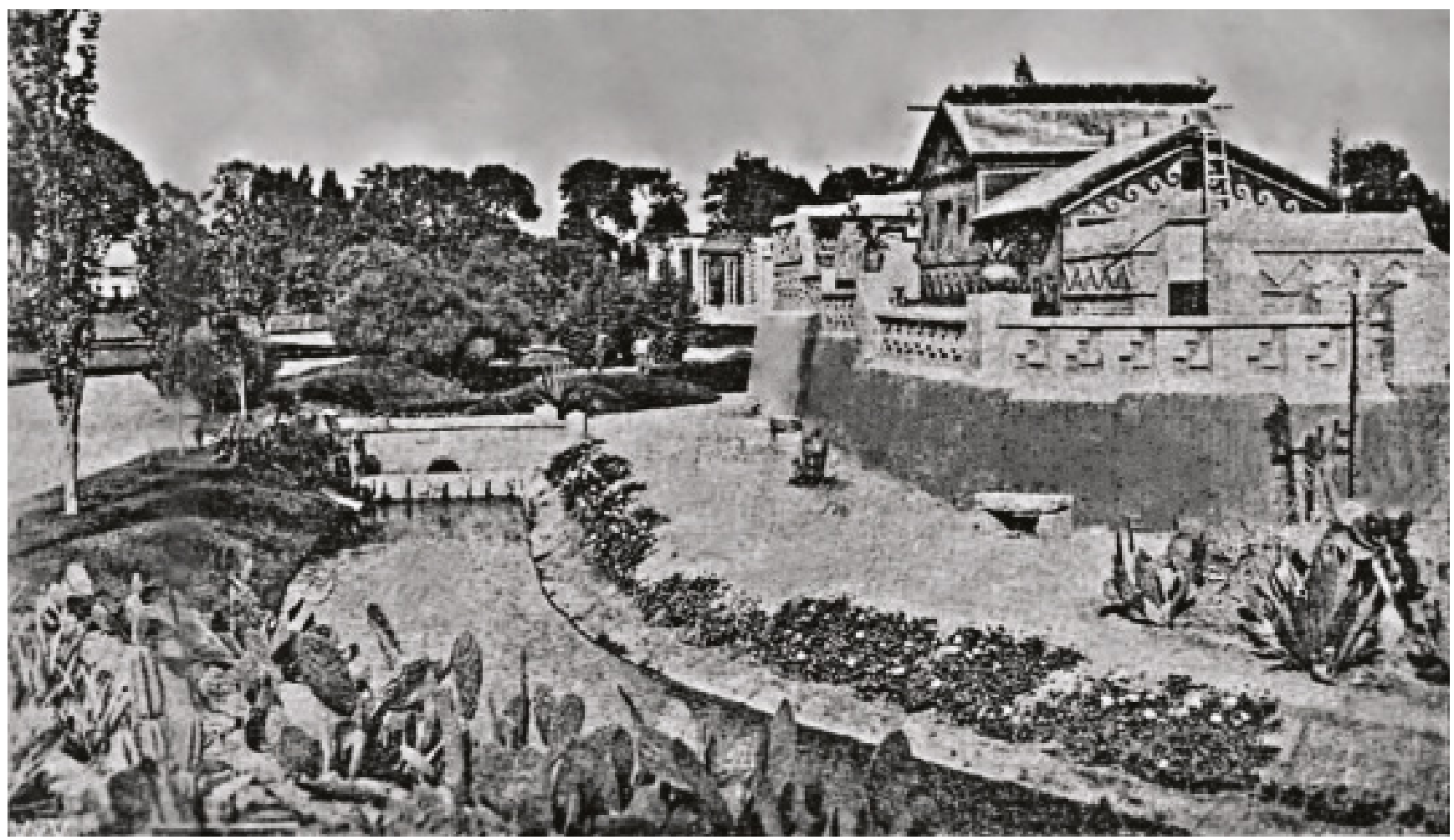

Figura 4. Huaca elaborada por José Sabogal, en el Parque de la Reserva. Ciudad y Campo y Caminos 43, 1929. Publicado por Gabriel Ramón, 2014.

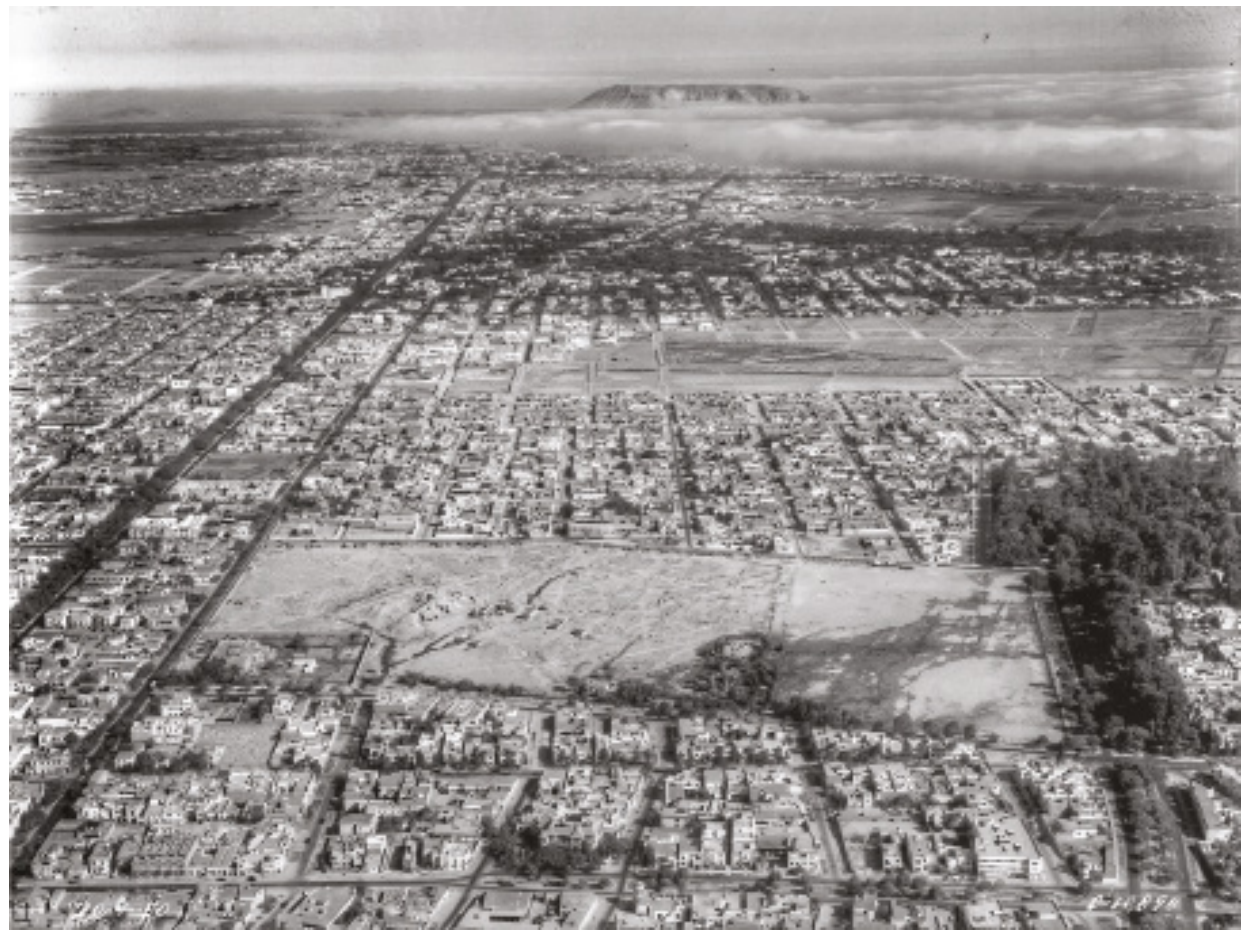

Figura 5. Fotografía oblicua de los campos de Santa Beatriz, al interior la Waka Santa Beatriz en proceso de destrucción. Servicio Aerofotográfico Nacional, 1944. Tomado de https://www.facebook.com/notes/ arqueolog\%C3\%ADa-jovelos/la-huaca-santa-beatriz/2454288784588121/, 2019. 
devenir Vol. 7, Nº13, ENERO - JUNIO 2020, PP. 121-134 - EsTUDIOS I ISSN 2312-7562 | E-ISSN 2616-4949

UNIVERSIDAD NACIONAL DE INGENIERÍA, LIMA

doi: https://doi.org/10.21754/devenir.v7i13.928

Y esto es importante porque entonces las huacas de Lima se tornan en materia de estudio, adquieren prestigio y empiezan a formar parte, así, del cuerpo de reliquias de la nación. Serán estas las lecciones que el poeta recibirá dentro y fuera de las aulas universitarias y dejarán la materia para la elaboración del poema a Machu Picchu. Serán estas aproximaciones las que generarán esa inicial oposición entre lo feble y la fortaleza, virtud a los lugares desde donde poder medir el espacio de residencia y poetizarla varios años después en La mano desasida. El poeta entonces considera parte del cuerpo de reliquias y materia poética a la gran llacta cusqueña (ver Figuras 3, 4 y 5).

De forma complementaria, hay que recordar que el Colofón de La casa de cartón fue escrito por José Carlos Mariátegui, quien en un tono divertido dirá que este libro «se asomó por primera vez al público desde las ventanas de "Amauta", tres anchos trapecios inkaicos como los de Tampuctocco, de donde están mensurando el porvenir los que mañana partirán a su conquista» (Adán, 1974, p. 89). A esta imagen mítica e incaica y su profético anuncio del largo poema a Machu Picchu, se deben agregar las propias ideas de Mariátegui para quien la razón científica no es suficiente en los desciframientos de la realidad, pues «mata la leyenda, destruye el símbolo (...) no nos ayuda a entender el Tawantinsuyo» (Mariátegui, 1988, p. 88), tan insuficiente como la aplicación de modelos foráneos en el arte peruano. A ello opone la originalidad y creatividad de los nuevos artistas quienes debían de buscar ambos objetivos en las culturas ancestrales. Con Amauta se crea un espacio para dar cabida a este afán. Y los que se acercaron a este fueron los artistas del Indigenismo y poetas como César Vallejo. Para Mariátegui « [e]l enigma del Tawantinsuyo no hay que buscarlo en el indio. Hay que buscarlo en la piedra» (Ibídem, p. 88-89). Pensemos otra vez en los versos citados arriba: «Déjame ser una piedra,/ Entre tus piedras y tus misterios,/ Déjame ser uno vivo».

Finalmente, en su tesis De lo barroco en el Perú, Adán afirmará que «España nos hizo a su imagen y semejanza». Y que, en esa línea, la literatura peruana e hispanoamericana deberían «no trocar nuestras entrañables barbaridades españolas por extraños símbolos universales» (citado por Westphalen, 1997, p. 337). Será Emilio A. Westphalen, quien en 1946 en su artículo De lo barroco en el Perú: una opinión adversa a la tesis de Martín Adán, opondrá con gran firmeza que

todos los que en el Perú abrieron camino y señalaron rumbo, todos a quienes sentimos en nuestra realidad, a quienes podemos interrogar y de quienes podemos esperar respuesta, todos fueron permeables a otros aires culturales, vieron el mundo más ancho y no temieron perder peculiaridad y esencia propia al contacto de otras personalidades y culturas, así fueran de Francia o China, de Noruega o Norte-América, de Rusia o el Congo, de España o Persia, así fueran, por fin, las propias culturas indígenas. (Westphalen, 1997, p. 339)

Esta situación nos ubica en el momento en que la antigua tradición hispana corre a la par con los aires universales de un poeta y un gestor como Westphalen, y de cuya síntesis con lo peruano, será uno de sus representantes. Tempranamente, en 1931, ya había expresado que se proponía «rebatir, atacar y oponer (...) el concepto clasicista e intelectual que de la poesía tiene Martín Adán», pues lo que Westphalen creía era que «lo poético es una expresión y registro de los pasos tomados en dirección a lo arcaico», a lo que denominó «poesía salvaje» (citado en Rebaza, 2017, p. 55). Se deduce que ambos contactos (uno privado en una carta a Xavier Abril en 1931 y otro público en 1946) también fueron reveladores para Adán y una razón más para la germinación del canto al gran monumento de la alteridad prehispánica.

\section{Fragmento arqueológico}

Debido a la extensión de La mano desasida y los temas textuales alrededor de él, nos planteamos dos interrogantes: ¿es posible hacer una interpretación total de algo incompleto o parcial? ¿O solo podemos interpretar por fragmentos? Una operación parecida a la de conocer los restos de un monumento, interpretándolo de forma total o parcial. 


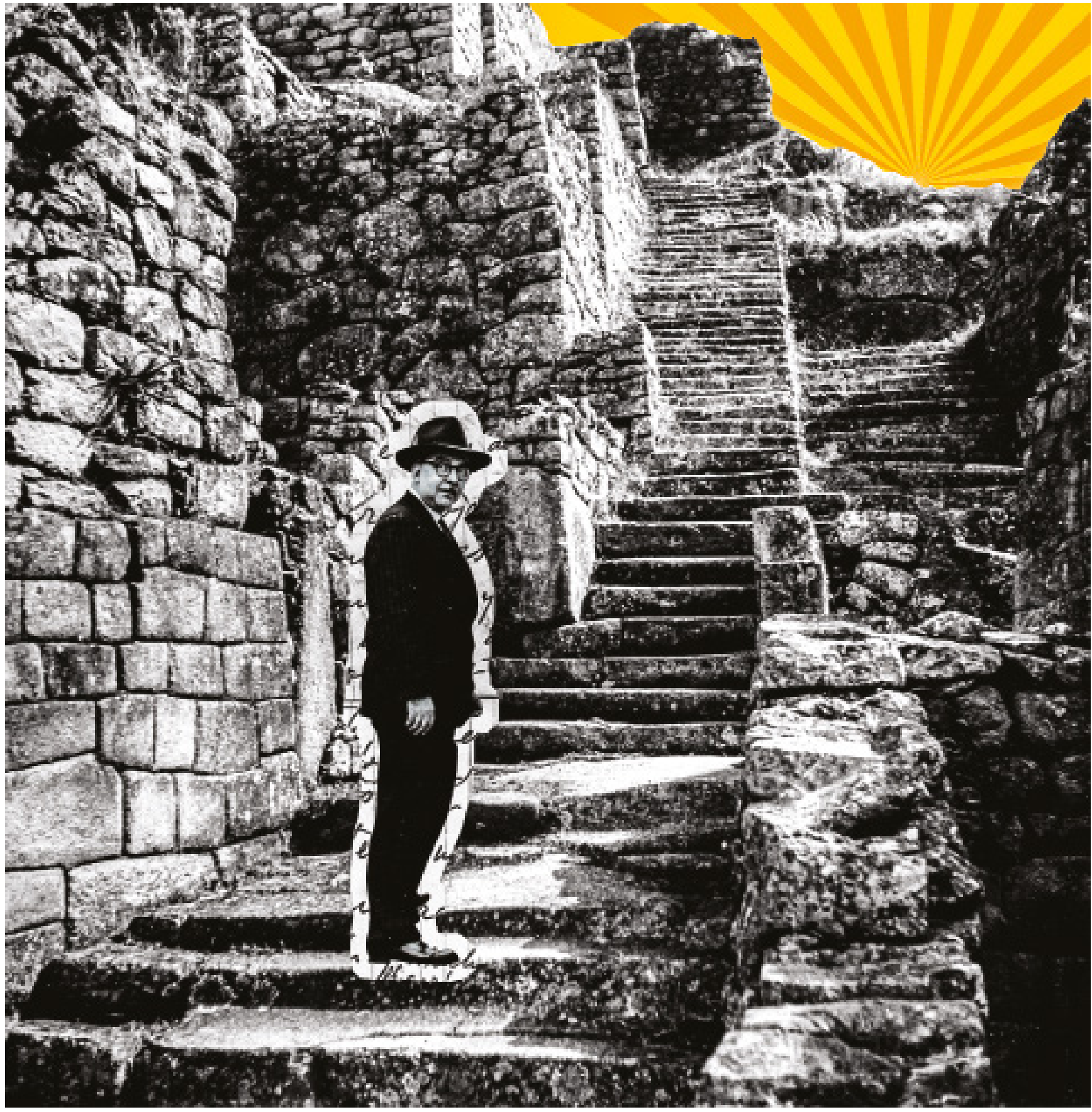

Esta es nuestra segunda dicotomía: fragmento verbal y arqueológico, que a su vez nos remiten a la idea de la totalidad en lo material y en lo verbal. Todo esto se suma a una cuestión de la elección del material y su estructura. Surgen nuevas interrogantes a partir de aquí. ¿Es realmente Machu Picchu un referente fragmentado e incompleto, tal y como ocurre con la génesis del texto total de La mano desasida? Según Franklin Pease: «Machu Picchu no es sólo un monumento, sino un conjunto ecológico y cultural que llegó casi intacto hasta el siglo XX, lo cual permite entenderlo mejor y explicarlo más ampliamente.
Figura 6. Composición de Martín Adán en Machu Picchu. Elaborado por Capibaras Editores, 2019. 
devenir Vol. 7, Nº13, ENERO - JUNIO 2020, PP. 121-134 - EsTUDIOS I ISSN 2312-7562 | E-ISSN 2616-4949

UNIVERSIDAD NACIONAL DE INGENIERÍA, LIMA

doi: https://doi.org/10.21754/devenir.v7i13.928

Es nuestra responsabilidad entregarlo así a la nuevas generaciones». (Mould, 2005, p. 1) En Ingeniería, revista peruana de Arte, Ciencia y Tecnología de 1965, el arquitecto Víctor Pimentel en relación a su estado y los trabajos que allí se habían realizado hasta ese año, declara de este monumento que «ha sido el que más atención y recursos ha tenido y cuya destrucción está más lejana que cualquier otro, porque su conservación, debido a los materiales y técnicas que utilizaron los Incas es bastante buena». (Beingolea, 2015, p. 106) Debido al colapso de la administración incaica, luego de la conquista española y el abandono de Machu Picchu en 1540 d.C. «[u]nos pocos edificios quedaron inconclusos, así como un nuevo canal secundario que se estaba construyendo en una terraza situada dos niveles más abajo del canal principal». (Kauffman, 2013, p. 436) (ver Figura 6)

Por otro lado, en Ollantaytambo, por ejemplo, la ausencia de totalidad que al pie de la montaña se puede ver en relación a fragmentos dispersos sobre el césped, es sorprendente, como si en realidad ese sector se tratara de un rompecabezas, y con ello nos diera una imagen acerca de la fragmentación de los hechos del pasado, debido a la presencia «de proyectos constructivos inconclusos» (Protzen, 2005, p. 14), sus incompletos testimonios y el proceso que lleva a su interpretación científica. Al respecto se dice

La zona planificada en damero no fue terminada. Todo el conjunto de Ollantaytambo estaba en construcción al momento de la conquista (...) Desde la plaza se pasa a la zona llamada"fortaleza" y"templo del Sol", ubicada en el tope de un escarpado peñón donde quedan muestras impresionantes de trabajos líticos inconclusos. Piedras enormes que parece fueron traídas de la cantera de kachitaka, ubicada en el cerro al otro lado del río Urubamba. (Gasparini, 1977, pp. 77-78) ${ }^{13}$

Según Lucien Dallenbach existen tres tipos de fragmentos, el clásico, el romántico y el contemporáneo. De ellos los dos primeros me parecen primordiales para hablar del poemario. En relación al fragmento clásico, se conserva una idea incompleta de una totalidad desconocida. Es decir, se ha perdido el conocimiento para comprender en su totalidad lo que llevan como testimonio los fragmentos de las ruinas grecolatinas.

According to this conception, the literary fragment similarly is a piece missing from the whole, whether of an unfinished work or a completed work that cannot be wholly reconstituted. In both cases the fragment is the product of destruction, whether of the work itself or of the creative process that has left the work unfinished. The classical fragment is the residue or the vestige of time in its character as decline, chance, and catastrophe. (Spurr, 2015, p. 29)

Es posible que Martín Adán asumiera el monumento como ruina incomprensible, rota, incompleta y muerta, y en su búsqueda de comprenderla como un reflejo de sí mismo, entonara un canto que viene y va y se fragmenta. En relación al fragmento romántico como forma, es Friedrich Schlegel quien expresaría que en poesía todo lo que está acabado puede estar incompleto, y todo lo incompleto formar, en realidad, algo acabado. Por ello pensamos estos dos conceptos partiendo de la existencia de una totalidad presente o velada en el caso de La mano desasida. Es importante tener claro el total del que el fragmento forma parte. En el caso específico de este poema, estaríamos ante fragmentos poéticos que atestiguan y son producto de la destrucción, del trabajo mismo, trabajo poético, o de ese mismo proceso que ha dejado algo inacabado y fragmentario de una totalidad que ¿ya no se puede alcanzar? En Indicios de una totalidad: el fragmento como forma, David Torella deduce que «no podemos llegar a captar la fragmentariedad en un objeto, teoría u obra si no podemos hacernos una idea por vaga que sea de la totalidad que la englobaría, si no la concebimos como parte de algo más vasto» ${ }^{14}$.

13. Una excelente reflexión sobre el devenir del monumento y las leyes que lo protegen pueden verse en el «Prefacio a la edición al castellano» de Arquitectura y construcción Incas en Ollantaytambo de Jean-Pierre Protzen, Machu Picchu patrimonio cultural en peligro de Alberto Martorell y Machu Picchu: un rompecabezas para armar de Mariana Mould de Pease.

14. Recuperado de http://www.ub.edu/las_nubes/archivo/18/indicios-totalidad Consulta jul. 2018 
Por otro lado, sobre la importancia de los testimonios del pasado, el antropólogo Luis Valcárcel fue una figura contemporánea para la cual «cualquier objeto, por insignificante que sea, contiene siempre una verdad reveladora. Nuestra historia precolombina carece de documentos; pero posee un copioso conjunto de monumentos que nos proporcionan datos importantísimos para restaurar esa parte considerable de nuestro pasado» (citado en Tantaleán, 2016, p. 95). Esa destrucción se complementa con la propia expansión del Tawantinsuyu y sus manifestaciones arquitectónicas en el territorio, hemos citado un par de casos de edificios no completados, cuando no fragmentos de totalidades no concretadas y cuyas funciones aún hoy permanecen bajo el velo del desconocimiento ${ }^{15}$.

En 1961-1964 el conocimiento de la alteridad prehispánica era bastante exiguo para un grueso sector de intelectuales. O no entraba dentro de sus intereses. Es evidente, por ejemplo, que ese desconocimiento le adjudicará el papel de algo muerto, separado, cuando no incomprensible en relación a lo prehispánico. Es Jorge Basadre, quien enuncia, refiriéndose a los Incas, su legado otorgado de forma indirecta como el territorio «y en forma directa una parte de nuestra población y también algunas lecciones y sugerencias que no siempre hemos aprovechado. Ello no obstante, su mundo espiritual es en sí un mundo extraño, lejano, muerto». (Basadre, 1968, p. 99)

Esto también es visible, en el poema de Martín Adán (en su acercamiento real o imaginado al monumento, en su elección como tema y espacio desde el cual realizar un canto aluvional, enlazando historia y vida) y en las vicisitudes fragmentarias en la edición del libro. En otras palabras: la imagen de la decadencia y el ocaso manifiestas en la vida del poeta y en su poesía, donde lo fortuito o azaroso desestructura lo que alguna vez estuvo completo y tenía significación (en la idea primigenia y el proceso de creación que se dispersa en las diferentes versiones editoriales). Y si podemos acceder a la totalidad del poema, será posible que junto al poeta desentrañemos el monumento desde su propio canto y a sí mismo luego de la catástrofe, el azar y el ocaso: el de Machu Picchu, el de una civilización y el suyo propio.

En ti está escrito,

Con tu letra enorme,

Toda la autobiografía

(Adán, 1980, p. 244)

Por otro lado, existe el precedente que pone al poeta frente al monumento, precisamente en el momento histórico del fragmento romántico y dentro de nuestra propia tradición. La República (próxima al Bicentenario) se abre precisamente con una aproximación parecida, pero en la costa frente a las ruinas de Pachacamac ${ }^{16}$.

\section{Epílogo}

Hemos rastreado las coordenadas prehispánicas en relación a su primera obra prosísti$\mathrm{ca}$, en sus elecciones de estudio de juventud, los maestros y amigos que le rodeaban, y

\footnotetext{
15. Sobre las posibilidades de reconstruir la totalidad o su parcial devenir en fragmentos, se puede leer sobre la investigación de Alexei Vranich de UC Berkeley, quien usando la data histórica, piezas impresas en 3D y un software de arquitectura ha logrado crear una reconstrucción virtual de Pumapunku, templo Tiahuanaco. El orden alcanzado en su modelo final, Vranich la explica así: "What we found out is that it appears they were making prototypes for each type of stone type, and then would have copied one after the other It's almost like it was a pre-Columbian version of Ikea." Nota en https://gizmodo.com/scientists-virtually-reconstruct-magnificent-pre-incan-1831051922?utm_medium=sharefromsite\&utm_source=gizmodo_twitter\&utm_campaign=bottom Consultado dic. 2018

16. Leer el artículo La Controversia Literaria Sobre «Las Ruinas de Pachacamac, Lima, 1822», de Luis Monguió, en el que se refiere a la creación de la Sociedad Patriótica por el entonces Protector del Perú, general José de San Martín, y refrendado por su ministro Bernardo de Monteagudo, y el acuerdo de ésta de publicar el periódico semanal El Sol del Perú, cuyo primer número apareció el 14 de marzo de 1822.
} 
devenir Vol. 7, Nº13, ENERO - JUNIO 2020, PP. 121-134 - EsTUDIOS I ISSN 2312-7562 | E-ISSN 2616-4949

UNIVERSIDAD NACIONAL DE INGENIERÍA, LIMA

doi: https://doi.org/10.21754/devenir.v7i13.928

luego la correspondencia entre la forma del poema (fragmentaria) y su propia elección del monumento prehispánico (fragmento arqueológico) para ser cantado. Es un tema de espacio (y sus dos condiciones: habitar y construir). Ahora nos toca oponer el fragmento arqueológico a la forma como se ha conocido hasta hoy el poema.

En el archivo Martín Adán de la PUCP, existen un total de $309^{17}$ documentos solo referidos al poema en un periodo que va desde $1961^{18}$ hasta 1980 . Incluso el testimonio del propio Mejía Baca acerca del criterio que le sirvió para la primera edición, debería ser tomado en cuenta: «[l]a poesía no es como para publicarla en obras completas, ni en volúmenes grandes. La poesía debe publicarse en libros pequeños de 60 páginas, ni más ni menos». (Vargas, 1992, p. 115)

No es evidente ni distinguible que desde su aparición en 1961 hasta su primera versión como libro en 1964, el orden y la cantidad de lo editado difiera de su conclusión en 1980. Los inicios y el orden no coinciden. Al respecto ya Luis Vargas explicaba que, al no encontrar un criterio de publicación, le entregó los documentos a tres críticos, escogió los fragmentos que seleccionaron, les dio un orden, y editó el libro La mano desasida, canto a Machu Picchu en $1964^{19}$ (Ibídem, p. 115). Y luego añade:

La edición de la poesía de Adán hecha por Ricardo Silva-Santisteban para el Banco Continental en 1980 recogió muchas de las partes inéditas de La mano desasida convirtiéndola en un volumen de casi 200 páginas. Silva-Santisteban siguió los textos mecanografiados que Mejía Baca le entregó y es evidente que aún quedan muchos textos inéditos que hubieran correspondido a ese libro, así como queda mucho que decir sobre su orden y la transcripción desde las, a veces, poco legibles libretas. (Ibíd., p. 115)

La edición de 1980 intentó a través de los textos mecanografiados presentar la totalidad del poema, pero no se ha profundizado sobre el tema de la forma en que apareció el poema. Podría una nueva edición salvar esa distancia, pero como ha venido sucediendo hasta aquí va a quedar en manos del editor el criterio de publicación. Mirko Lauer asegura que:

No debe descartarse la conveniencia de un reordenamiento de algunos elementos del poema, una depuración del orden originalmente dado por el rescate de los fragmentos al desorden cotidiano del autor. Pero en cualquier caso, el poema no es leíble todavía como una sola unidad. Falta que el Perú se familiarice con él. Precisa más lectura y más lectores, para que la recomposición de sus centenares de detalles vaya introduciendo entre nosotros una imagen cabal de éste el más importante poema individual de nuestro siglo XX, y tal vez de toda la literatura. (Adán, 1988, p.52)

17. Esto se puede consultar en línea: http://repositorio.pucp.edu.pe/index/handle/123456789/64294

18. Esta es la segunda aparición de La mano desasida, pues la primera fue en el Boletín Cultural Peruano $\mathrm{N}^{\circ} 9$ Lima, abril junio de 1961 pp. 4-5. No obstante, Vargas Durand asegura que «[l]a primera noticia de La mano desasida proviene de un recibo del Ministerio de Educación del 25 de mayo de 1961 en el que se dan por recibidos los originales para el premio de Fomento». (Vargas, 1992, p. 114) Cabe resaltar que la edición de La mano desasida de 1964 reproduce en su portada una cerámica que se dice mochica. En relación al hecho puntual del viaje al Cusco, por ejemplo, José Antonio Bravo dice que en el año de la entrevista citada 1954: «empieza un largo viaje por la sierra que se interrumpe en Ayacucho en donde se encuentra con José Ricaldone Respaldiza. Don José lo ve en la Plaza de Armas sentado en la vereda conversando con un indio de la zona en un quechua inmasticable, pero unidos por una botella de aguardiente. Nadie supo nunca si Martín Adán hablaba quechua, pero a decir de don José la comunicación era, aparentemente, muy fluida». (Bravo, p. 55) Sobre las apariciones de La mano desasida se puede consultar la edición de 1980 de su Obra Poética editada por Ricardo Silva Santisteban o la del 2006, que sigue el mismo criterio.

19. En el libro Poesía, ser y quimera. Estudio de La mano desasida de Martín Adán de Jim Anchante, se afirma que en conversación con Ricardo Silva Santisteban, éste le mencionó al autor que Mejía Baca le confió que dos de los críticos convocados para leer los fragmentos de La mano desasida, seleccionados para la edición de 1964, fueron Luis Monguió y Alberto Escobar (Anchante, 2012, p. 52). El dato importante aquí es el de Luis Monguió, quien señalamos es el autor del estudio de Las ruinas de Pachacamac, el cual pudo escribirse gracias a los materiales recogidos en Lima en el verano de 1960 y se presentó el 28 de diciembre de ese mismo año a un grupo de trabajo. 
En relación a La mano desasida, el orden de las libretas ${ }^{20}$ del poeta están puestas según un orden cronológico. Gracias a Julio Núñez del Archivo Martín Adán en la PUCP, sabemos que Juan Mejía Baca al recibirlas del poeta iba sellando las entregas. Aquellas que no tienen dicho sello van hacia el final de dicho orden. La primera recepción es del 4 de abril de 1961, lo mismo ocurre en 1962, 1963 y 1964. Luego de ese grupo de manuscritos tenemos las hojas mecanografiadas de 1964 y la de 1980. Finalmente las libretas que contienen versos inéditos vinculados con el poema que no tienen fecha, sin embargo dentro de los periodos temporales anteriores también existen partes inéditas.

Los objetivos para una nueva mirada al poema y una propuesta total, sería determinar lo que ya se publicó en la edición de 1980, asimismo determinar cuál fue la totalidad para la edición del 61 y la del 64. Precisar las variantes de lo inédito en relación a lo ya publicado en esas ediciones, revisar la correspondencia con Juan Mejía Baca, así como aquellas comunicaciones que se encuentran dentro de las libretas con poemas relacionados a La mano desasida y que echen luces sobre las intenciones del autor, las cuales, sin embargo, se encuentran corroboradas en las versiones editoriales publicadas.

Un análisis de los documentos nos daría una idea de la totalidad del poema. Así como el proceso de las tres etapas cronológicas en las que el poema se fue gestando, su relación con otros poemas alrededor de él, algunas notas personales para otros escritores y pedidos editoriales a Juan Mejía Baca, en vista a crear dos diferentes trabajos: a) establecer una nueva totalidad del poema y b) editar una pequeña versión que englobe una idea unitaria del poema ${ }^{21}$. Esta debería ser una nueva publicación que supere a las anteriores con vistas a los 60 años de su primera publicación fragmentaria en 1961.

\section{Referencias}

Adán, M. (1964). La mano desasida. Lima, Perú: Juan Mejía Baca (Edit.).

Adán, M. (1974). La casa de cartón. Lima, Perú: Ediciones Peisa.

Adán, M. (1980). Obra poética. Lima, Perú: Edubanco.

Adán, M. (1988). Antología poética. Madrid: Visor Libros.

Anchante, Jim (2012). Poesía, ser y quimera. Estudio de La mano desasida de Martín Adán. Lima, Perú: Vicio perpetuo.

Basadre, J. (1968). Ante el problema de las élites. Lima, Perú.

Beingolea, J. (2015). Víctor Pimentel Gurmendi y el patrimonio monumental. Textos escogidos. Lima, Perú: Editorial Universitaria.

Bravo, J. (1988). Biografía de Martín Adán. Lima, Perú: Biblioteca Nacional del Perú.

Crousse, V. (2011). Reencontrando la espacialidad en el arte público del Perú (Tesis presentada para la defensa del grado de Doctor). Universidad de Barcelona, Barcelona.

Gasparini, G. \& Margolies, L. (1977). Arquitectura Inka. Caracas: Centro de Investigaciones Históricas y Estéticas. Facultad de Arquitectura y urbanismo. Universidad Central de Venezuela.

\footnotetext{
20. Las libretas están divididas en Partes, del I al VII, y se denominan «Libreta que contiene versos manuscritos vinculados con el poema La mano desasida».

21. Esta sección por una cuestión de espacio no podrá ser desarrollada en el presente artículo. Esta iba a partir del análisis y comparación con tres ensayos discursos del filósofo Martin Heidegger. Construir Habitar Pensar, ...Poéticamente habita el hombre... y Hörderlin y la esencia de la poesía. El segundo de ellos ya había sido comentado en la edición de 1980 por Silva Santisteban. Hasta aquí habíamos visto la idea de lo feble opuesto a la fortaleza, conocimiento y destrucción, totalidad y fragmento. Una vez más iba a regresar a la idea de habitabilidad con la que abrí este artículo en relación a la materia de la estructura con que se construye, pero esta vez entendiendo el habitar en el poetizar. Es decir, la idea de habitar como medida del ser, y, por otro lado, la forma como se mide esa residencia a través de la poesía. «Ser hombre significa estar en la tierra como mortal, significa habitar. La antigua palabra bauen significa que el hombre es en la medida en que habita». (Heidegger, Construir Habitar Pensar, p. 2) Finalmente venía con ello aparejado el proteger y su relación con las preocupaciones cívicas sobre arte de Martín Adán en sus notas del Archivo.
} 
devenir Vol. 7, Nº13, ENERO - JUNIO 2020, PP. 121-134 - EsTUDIOS I ISSN 2312-7562 | E-ISSN 2616-4949 UNIVERSIDAD NACIONAL DE INGENIERÍA, LIMA

doi: https://doi.org/10.21754/devenir.v7i13.928

Graña, M. (Comp.) (2006). La suma que es el todo y que no cesa: el poema largo en la modernidad. Rosario, Argentina: Beatriz Viterbo (Edit.).

Heidegger, M. ...Poéticamente habita el hombre... Recuperado de https://semanariorepublicano.uchile.cl/index.php/RDF/article/download/.../46941. Consultado jun. 2018

Heidegger, M. Construir Habitar Pensar. Recuperado de http://www.geoacademia.cl/docente/ mats/construir-habitar-pensar.pdf. Consultado junio, 2018.

Heidegger, M. Hörderlin y la esencia de la poesía. Recuperado dehttps://revistas.upb.edu.co/index.php/upb/article/viewFile/3444/3037. Consultado junio, 2018.

Kauffman, F. (2013). Machu Picchu. Sortilegio en piedra/ Enchatment in stone. Lima, Perú: Universidad Alas Peruanas.

Kubler, G. (1948). Sobre arquitectura actual en Lima. Las Moradas. Octubre, Volumen II. (6), pp. 263-269.

Lauer, M. (1983). Los exilios interiores. Una introducción a Martín Adán. Lima, Perú: Hueso Húmero ediciones, 1983.

Mariátegui, J. C. (1988). Peruanicemos al Perú. Recuperado de http://www.archivochile.com/ Ideas_Autores/mariategui_jc/s/Tomo11.pdf, Consultado enero, 2020.

Martorell, A. (2000). Machu Picchu: patrimonio cultural en peligro. Lima, Perú: Malze.

Meyer, Karl E. (1973). The plundered past. Nueva York: Atheneum.

Milla, M. (1954) Cultura Peruana. Revista Mensual Ilustrada. Abril. Vol. 14 (70), s.n.

Monguió, L. (1961). Las ruinas de Pachacamac. Revista Iberoamericana. Enero-junio, Vol. XXVI (51), pp. 81-110.

Moro, C. (2002). Prestigio de amor. Lima, Perú: Pontificia Universidad Católica del Perú.

Mould de Pease, M. (2005). Un rompecabezas para armar. Revista Andina. Segundo semestre (41), pp. 199-220.

Neruda, P., Hidalgo A., Adán, M. (1961). Nuevas piedras para Machu Picchu. Lima, Perú: Juan Mejía Baca (Edit.)

Piñeiro, A. (Edit.) (2011). Entrevistas. Lima, Perú: Pontificia Universidad Católica del Perú.

Proetzen, J. (2005). Arquitectura y Construcción Incas en Ollantaytambo. Lima, Perú: Fondo Editorial de la Pontificia Universidad Católica del Perú.

Ramón, G. (2014). El neoperuano: arqueología, estilo nacional y paisaje urbano en Lima, 1910-1940. Lima, Perú: Municipalidad Metropolitana de Lima y Sequilao Editores.

Ravines, R. (1985). Inventario de monumentos arqueológicos del Perú: Lima Metropolitana [primera aproximación]. Lima, Perú: Instituto Nacional de Cultura y Municipalidad de Lima Metropolitana.

Rebaza, L. (2000). La construcción de un artista peruano contemporáneo: poética e identidad nacional en la obra de José María Arguedas, Emilio Adolfo Westphalen, Javier Sologuren, Jorge Eduardo Eielson, Sebastián Salazar Bondy, Fernando de Szyszlo y Blanca Varela. Lima, Perú: Fondo Editorial de la Pontificia Universidad Católica del Perú.

Rebaza, L. (2017). De ultramodernidades y sus contemporáneos. Lima, Perú: Fondo de Cultura Económica.

Ribeyro, J. (2000). La palabra del mudo. Lima, Perú: Editora El Comercio.

Rodríguez Larraín, S. (1983-1984). Adobe. (Tesis presentada para la defensa del grado de Bachiller). Universidad Nacional de Ingeniería, Lima, Perú.

Spurr, D. (2015). Architecture and Literature. Michigan: The University of Michigan Press.

Tantaleán, H. (2016). Una historia de la arqueología. Lima, Perú: IEP Instituto de Estudios Peruanos.

Torella, D. Indicios de una totalidad: el fragmento como forma. Recuperado de http://www.ub.edu/ las_nubes/archivo/18/indicios-totalidad Consultado agosto 2018.

Vargas Durand, Luis (1992). Biografía de Martín Adán. Recuperada de http://biblioteca.pucp.edu. pe/martin-adan/bio/biografia.doc Consultado agosto 2018.

Westphalen, E. (1997). Escritos varios sobre arte y poesía. Lima, Perú: Fondo de Cultura Económica.

Zegarra, C. (2008). Un país de beaver board: cinematografía y nación desechable en La casa de cartón de Martín Adán. INTI, (67-68), 81-96. 